\title{
Librarians' behavioral performance on chat reference service in academic libraries: Perceived importance us actual practices
}

\author{
Nor Azilawati Mohd Azmi ${ }^{1}$, A. Noorhidawati ${ }^{2}$ and M.K.Yanti Idaya Aspura ${ }^{2}$ \\ ${ }^{1}$ Perpustakaan Tun Abdul Razak, UiTM Cawangan Pulau Pinang, \\ Kampus Permatang Pauh, Pulau Pinang, MALAYSIA \\ ${ }^{2}$ Department Library and Information Science, \\ Faculty of Computer Science and Information Technology, \\ University of Malaya, Kuala Lumpur, MALAYSIA \\ e-mail: norazilawati348@ppinang.uitm.edu.my; \\ noorhidawati@um.edu.my (corresponding author); yanti@um.edu.my
}

\begin{abstract}
Having established from researches that the Reference and User Service Association (RUSA) Guidelines for Behavioral Performance is widely accepted and used as a reference to evaluate a reference interaction, this study made a comparison of perceived importance and actual practice of the guidelines for chat reference service among academic librarians. The Behavioral Performance of Reference and Information Service published by RUSA was used in the development of the survey instrument. The study employed a quantitative approach to address the following research objectives: (a) to determine academic librarians' perceived importance and current practices of behavioral performance in the interaction during the chat reference service; and (b) to assess the association between academic librarians' perceived importance and actual practices of behavioral performance in the interaction during the chat reference service. A survey was administered to 92 librarians from six academic libraries in Malaysia which offer chat reference service to their users. A response rate of 84.8 percent was achieved resulting in 78 usable questionnaires to be analysed. The finding in general demonstrates that the majority of the librarians rated perceived importance higher than actual practices. The mean gap between perceived importance of RUSA guideline and the level of practices among librarians is beneficial to identify areas in chat reference services that need improvement. The findings could provide an empirical benchmark for evaluating chat reference services. It was recommended that librarians' perceived importance of the chat reference should not be used as the basis for understanding their actual practices of the service.
\end{abstract}

Keywords: Chat reference service; Academic librarians; Guidelines; Behavioral Performance; Reference and User Service Association (RUSA); Gap Analysis.

\section{INTRODUCTION}

Technology advancements have changed the way libraries provide reference services to their patrons particularly through virtual reference. Virtual reference has been developed to assist library users to seek information and consult librarians, often in real time, without 
being physically present in the library. Apart from instant messaging and web based chat reference, librarians also offer reference services virtually via web conferencing tools, such as Adobe Connect (Arvin and Kaiser 2012), Web 2.0 tools such as Twitter (Arya and Mishra 2011; Beaton 2012), Facebook and Twitter (Chu and Du 2012); mobile devices, such as WeChat (Pun 2015), Whatsapp (Akeriwa, Penzhorn and Holmner 2014) and Skype (Beaton 2012). These services are initiated by the libraries in order to meet users' needs, pursue virtual reference technologies (Yang and Dalal 2014) and improve library services (O'Dell 2010).

For quality assurance chat reference services have been evaluated from time to time. The evaluation of chat references services were conducted in several ways such as through assessment of the service quality (Armann-Keown, Cooke and Matheson 2015; Fuller and Dryden 2015; Radford and Connaway 2012), user satisfaction (Hill, Madarash-Hill and Allred 2007) and also by comparing the perceived importance and actual practices among users or the service providers (Jaarsma et al 2010; Al-Momani 2016) to identify the differences between measures, e.g. what is believed and the actual practices.

In assessing chat reference services, several guidelines could be use as the benchmark such as RUSA (Reference and User Service Association) Guidelines for Behavioral Performance of Reference and Information Service Providers ${ }^{1}$; or RUSA Guidelines for Implementing and Maintaining Virtual Reference services ${ }^{2}$; or International Federation of Library Associations and Institutions (IFLA) Digital Reference Guidelines ${ }^{3}$. As the RUSA Guidelines for Behavioral Performance is widely accepted and used as reference in the literature to evaluate a reference interaction (Ronan, Reakes and Ochoa 2006), this study utilizes RUSA guidelines as the benchmark to compare the behaviors academic librarians perceived as important and the behaviors that are current being practised while conducting the chat reference service. This study reports the gap between the perceived importance and the actual practices of the behavioral performance in the interaction during the chat reference service among the librarians.

\section{Chat Reference Services}

The advent of the Internet has given a tremendous effect on reference services in libraries. Chowdhury and Margariti (2004) stated that technological innovation has changed the way libraries provide information services to the users and how users choose to access the information. Internet has transformed the traditional reference services into virtual reference services commonly known as "digital reference", "online reference service", "virtual reference interview" and "Ask a Librarian."

Digital reference provides a convenient access to reference service. One way of delivering a digital reference service is through chat reference services that provides synchronous digital communication applications via the Internet, providing the librarian and patron with a realtime computer conferencing system that allows two or more persons to chat online at the same time (Schwartz 2014). Users could get immediate assistance to fulfill their information needs regardless of physical location. This has also become an effective method to deliver an instant reference service to remote user populations.

\footnotetext{
${ }^{1}$ Available at http://www.ala.org/rusa/resources/guidelines/guidelinesbehavioral

${ }^{2}$ Available at http://www.ala.org/rusa/sites/ala.org.rusa/files/content/resources/guidelines/virtualreference-se.pdf

${ }^{3}$ Available at http://www.ifla.org/files/assets/reference-and-information-services/publications/ifladigital-reference-guidelines-en.pdf
} 
In general, digital reference service has to deal with several aspects such as technical requirement, funding, support, policy, staffing, training, audience, evaluation and improvement, service behaviors, marketing, privacy, and legal issues (RUSA 2010) that require an established and accepted guidelines for a successful service. As this service continues to grow, it faces a great challenge mainly due to the lack of visual clues and cues during the online interaction particularly in handling different needs of users (Platt and Benson 2010; Maximiek, Rushton and Brown 2010). A key issue for all libraries is to identify the best way of providing asistance to users. Hence, there is a clear need for guidelines in order to ensure service quality and successful reference transaction.

Fullerton (2002) claims that the need for guidelines and standards is very important as a digital reference introduces new issues and challenges as well as with development of consortium-wide virtual reference services. Shachaf and Horowitz (2006) indicate that the use of professional guidelines would help librarians to systematically evaluate the quality of digital reference services.

Guidelines can provide standard criteria for evaluating the performance of reference services and librarians (Gatten and Radcliff 2001; Saxton and Richardson 2002) and use it to assist in the training and development of reference and information services (RUSA 2013). Morin (2004) mentioned that guidelines indicate a procedure that can improve effectiveness and efficiency of digital reference service by outlining a quality services characteristic and new assessment measures. Kwon and Gregory (2007) reported that user satisfaction regarding chat reference service was statistically significantly higher when practising RUSA behavior guidelines such as when the librarians listen and communicate effectively, demonstrate expertise in searching, and invite the user back to the service if they have further questions.

\section{RUSA Guidelines for Behavioral Performance of Reference and Information Service Providers}

RUSA Guidelines for Behavioral Performance of Reference and Information Service Providers (2004) indicated that the success of the transaction is evaluated both by the information conveyed and by the behavior of the librarians in the interaction (as observed by the patron). Therefore, in order to provide high quality services to users, librarians not only need to be well trained in searching and locating the information, but also learn the art of courtesy, helpfulness and have a good communication and interpersonal skills. Additionally, Kwon and Gregory (2007) and Maness, Naper and Chaudhuri (2009), expressed their opinion that librarians who are practicing RUSA Guidelines in a chat reference service can provide a better service to users and increase user satisfaction.

The guidelines ${ }^{4}$ published by RUSA is as an effort to help librarians improve user - librarian interaction both in person and online reference. It suggests ideal behaviors for librarians in reference transaction that can contribute to a higher level of service. RUSA Behavioral Guidelines (RUSA 2013) outlined the following behavioral performance of reference and information service providers:

(a) Visibility/Approachability: Reference librarian is available to assist a user and make them feel comfortable to ask a question;

(b) Interest: The librarian shows an interest to the user question;

${ }^{4}$ Available at http://www.ala.org/rusa/resources/guidelines/guidelinesbehavioral 
(c) Listening/Inquiry: The librarian provides reference interview as well as practicing effective listening and questioning skills;

(d) Searching: The librarian demonstrates effective information search skills to answer the user inquiry; and

(e) Follow-up: The librarian asks users' satisfaction on the information provided and refer them to other locations of information if not available in the library.

\section{LITERATURE REVIEW}

The literature on digital reference evaluation particularly on online chat reference has grown significantly in the past few years. The evaluation of reference service in digital environment is still based on the same principles used in traditional face-to-face reference services. The literature has indicated reference evaluation studies were conducted based on two perspectives: (i) service perspective; and (ii) user perspective.

Studies on service perspective has looked into type of questions being asked during the chat interaction (Armann-Keown, Cooke and Matheson 2015; Arnold and Kaske 2005; Fuller and Dryden, 2015; Radford and Connaway, 2012). Examining the type of users' questions has provided better understanding of users' information needs. Generally, the studies develop the reference question categories based on known-item search questions, directional questions, reference questions, (ready reference and specific-search reference) and research questions. Some studies measures quality of chat reference transactions through accuracy and completeness of reference answers and usefulness of the service (Fuller and Dryden 2015; Valentine and Moss 2017). Another important aspect of chat reference evaluation from the service perspective is the behavior of the librarians as they attempt to respond to the query since visual and verbal cues are not present during the chat reference transaction. A few studies analysed whether librarians' performing RUSA behavioral guidelines during chat sessions (Naper and Chaudhuri 2009; Maximiek, Rushton and Brown 2010; Platt and Benson 2010; van Duinkerken, Stephens and MacDonald 2009;) or if the librarians offered library instruction through chat service (Devlin, Currie and Stratton 2008; Desai and Graves 2008; Matteson, Salamon and Brewster 2011; Valentine and Moss 2017). Most evaluation on librarians' behavior and performance was conducted based on chat reference transcripts that were examined for evidence of adherence or not to the RUSA guidelines and behaviors.

Studies on user perspective normally focus on users' satisfaction that include differences in satisfaction between complete answers and referrals (Kwon 2006); the factors that contribute to satisfaction/dissatisfaction with chat (Nilsen and Ross 2006; Pomerantz and Luo 2006); satisfaction with outsourced chat service (Hill, Madarash-Hill and Allred 2007); and user satisfaction related to librarians' behaviour based on RUSA guidelines during chat sessions (Kwon and Gregory 2007). Findings from these standpoints indicated that users tend to be more satisfied when they received complete answers and when the librarians performed listening and communicating, demonstrating expertise in searching and offering pointers, and inviting the user back to the service if they had further questions.

However, studies on service evaluation was also conducted by comparing user's perceived importance and actual practices while delivering the service such as in teaching (Philips and Borg 2009), nursing (Jaarsma et al. 2010), digital library services (Lagzian, Abrizah and Wee 2015) and health (Al-Momani 2016). These comparison evaluations provided empirical insight on the gap that can arise from user perception and actual practices in order to 
understand user behaviour. This is particularly important to gauge if what users belief were corresponding with what they practices. In general, those studies discussed earlier provide a descriptive view of various aspects of chat reference evaluation using different measures in order to further improve the overall performance of chat reference services.

\section{OBJECTIVES AND METHOD}

The main objective of this study is to compare academic librarians' perceived importance and actual practices of behavioral performance in the interaction during the chat reference service according to RUSA Guidelines for Behavioral Performance. In order to address this research objective, the following research questions were put forward:

(a) What is the academic librarians' perceived importance and actual practices of behavioral performance in the interaction during the chat reference service?

(b) What is the gap between academic librarians' perceived importance and actual practices of behavioral performance in the interaction during the chat reference service?

This study uses a quantitative exploratory descriptive research design. A survey questionnaire was used to gather the data. The survey instrument has been developed based on RUSA (2013) guideline for behavioral performance of reference and information service. RUSA guideline is choosen because it has been widely used in training, development and evaluation of information services in library setting.

The survey instrument consists of two parts, the first part is to assess librarians perceived importance of behavioral performance in chat interaction using 5-point Likert scale of importance: 1= Not Important; 2= Slightly Important; 3=Moderately Important; 4=Important; 5=Very Important (Brown 2010). The other part is assessing the librarians actual practices that are measured using 5-point Likert scale: 1=Never; $2=$ Almost Never; 3=Sometimes; 4=Almost Every Time; 5=Every Time (Vagias 2006).

The survey questionnaire were distributed to six academic libraries that provide chat reference services to their users. Random sampling was used involving librarians as the unit of analysis. The sample size is 92 out of 110 population size to achieve a 95 percent confidence level based on Krejcie and Morgan (1970) sampling formula. E-mail invitations with link to the online survey were sent out to the target respondents within three months from August to October 2016. A reminder note was emailed to the respondents in September to complete the survey. As a result, a total of 78 responses were gathered that made up a 84.8 percent response rate.

The analysis was conducted using frequency and mean in order to answer the first research questions. The second research question was analysed using mean gap. Mean gap score is used to identify gap between users' perception and actual practices, typically applied in evaluating service performance or quality assessment (Brown and Swartz 1989; Lagzian, Abrizah and Wee 2015; Al-Momani 2016). The calculation of the mean gap score is as follow:

Mean Gap Score $=$ Mean of Perceived Important (I) - Mean of Actual Practices (P)

From the total of 78 responses, 39.7 percent (31) of the respondents were male, while 60.3 percent (47) were female. A total of 55.1 percent (43) of the respondents hold a Master Degree, 43.6 percent (34) had a Bachelor Degree whilst the remaining 1.3 percent (1) had earned a PHD. Most of the respondents were Senior Librarians (56.4 percent, 44), followed 
by Librarians (33.33 percent, 26) and Deputy Chief Librarians (10.3 percent, 8 ). The findings indicate that most of the respondents have experience as a Reference Librarian who assist, advise, and instruct users in accessing all forms of recorded knowledge. About 28.2 percent (22) of the respondents indicated Reference Librarian as their current position while 46.2 percent (36) of the respondents specified Reference Librarian as their previous position. Another 25.6 percent (20) of the respondents had never held position as reference librarian. However these respondents reported had carried out their duty in chat reference service for one to eight hours per day.

When asked the platforms they used for chat reference service, the respondents reported the following: LibChat (http://ptar.library.uitm.edu.my/libchat/lhc_web); Ask a Librarian (http://library.oum.edu.my/oumlib/ask-librarian, http://library.utem.edu.my/en/asklibrarian.html); tawk.to (http://vlib.mmu.edu.my/library/\#max-widget); and lib-consultant (http://www2.utem.edu.my/libconsultant/client.php?locale=en\&url=http\%3A//library.ute m.edu.my/en/ask-librarian.html\&referrer=http\%3A//library.utem.edu.my/en/). These live chat platforms allow the user to use instant messaging to contact the librarian via library website.

\section{FINDINGS}

The findings as tabulated in Table 1 show the overall mean of perceived importance and actual practices of five behavioral performance during chat reference service in accordance to RUSA guidelines, namely Visibility/Approachability, Interest, Listening/Inquiring, Searching and Follow Up.

\section{Academic librarians' Perceived Importance and Actual Practices of Behavioral Performance in the Interaction during the Chat Reference Service}

Academic librarians' perceived importance and actual practices of behavioral performance in the interaction during the chat reference service are based on the following characteristics:

a) Visibility/approachability:

- Item 2: "acknowledges patrons by using a friendly greeting to initiate a conversation and willingness to help" indicated the highest mean $(M=4.54)$ in perceived importance with 61.0 percent of the respondents expressed it is as $5=$ very important.

- Similarly Item 2 was exhibited the highest mean $(M=4.18)$ of actual practices with 48.7 percent of the respondents rated it as $4=$ almost every time

b) Interest:

- Item 3: "provide assurance that the query is still viable and a response is forthcoming" is perceived as the important with the highest mean $(M=4.42)$ and 51.3 percent of the respondents indicated it as $5=$ very important.

- Item 1: "focuses complete attention on the patron and his/her information need" is indicated as highest mean $(M=4.14)$ with 52.6 percent of the respondents rated it as $4=$ almost every time. 
c) Listening/Inquiring:

- Item 10: "respect patron privacy; maintain confidentiality after the transaction" was rated as the highest mean $(M=4.54)$ with 59.0 percent of the respondents stated it as $5=$ very important.

- Similarly item 10 indicated as the highest mean $(M=4.38)$ with 51.3 percent of the respondents rated it in actual practices as $5=$ every time.

d) Searching :

- Item 7: "explains the patron how to use sources when appropriate" is the most important behavior with the highest mean $(M=4.42)$ and 50.0 percent of the respondents expressed that the behavior is $5=$ very important.

- Item 3: "explains the search strategy to the patron" demonstrated the highest mean $(M=4.29)$ with 47.4 percent of the respondents rated it as $5=e v e r y$ time.

e) Follow Up :

- Item 1: "asks the patron if his/her questions have been completely answered" have the highest mean $(M=4.50)$ with the highest percentage of 56.4 percent is indicated by $5=$ very important.

- Item 4: "makes the patron aware of other available reference pathways (email, face to face reference)" recorded the highest mean ( $M=4.22)$ with over half $(59 \%)$ of the respondents exhibited the behavior as $4=$ almost every time $=4$.

\section{Gap between Academic Librarians' Perceived Importance and Actual Practices of Behavioral Performance in the Interaction during the Chat Reference Service}

Mean gap score is used to identify gap between librarians' perception and actual practices of their behavioral performance in the interaction during chat reference service. Table 2 shows the gap rank between perceived importance and current practices of five behavioral performance in the interaction during the chat reference service according to RUSA guidelines.

Table 2: Mean Gap Rank of RUSA Behavioral Performance in Chat Reference Service

\begin{tabular}{lccccccc}
\hline \multirow{2}{*}{$\begin{array}{l}\text { RUSA Guidelines } \\
\text { Categories }\end{array}$} & $\begin{array}{c}\text { Total } \\
\text { Number } \\
\text { of Item }\end{array}$ & \multicolumn{2}{c}{$\begin{array}{c}\text { *Perceived } \\
\text { Importance }\end{array}$} & \multicolumn{2}{c}{$\begin{array}{c}* \text { Current } \\
\text { Practices }\end{array}$} & \multirow{2}{*}{$\begin{array}{c}\text { Mean } \\
\text { Gap }\end{array}$} & $\begin{array}{c}\text { Gap } \\
\text { Ranking }\end{array}$ \\
\cline { 3 - 6 } & 6 & 4.425 & 0.563 & 4.051 & 0.672 & 0.374 & 1 \\
Visibility/ Approachability & 6 & 4.390 & 0.596 & 4.040 & 0.673 & 0.350 & 2 \\
Interest & 10 & 4.394 & 0.518 & 4.156 & 0.637 & 0.238 & 4 \\
Listening/ Inquiring & 10 & 4.323 & 0.602 & 4.141 & 0.662 & 0.182 & 5 \\
Searching & 7 & 4.391 & 0.538 & 4.108 & 0.631 & 0.283 & 3 \\
Follow Up & 7 & Mean & SD & & \\
\hline
\end{tabular}

* 1= Not Important; 2= Slightly Important; 3=Moderately Important; 4=Important; $5=$ Very Important

**1=Never; 2=Almost Never; 3=Sometimes; 4=Almost Every Time; 5=Every Time

The overall results reported that Visibility/Approachability has the highest gap (0.374) between perceived importance $(M=4.425)$ and current practices $(M=4.051)$. Under this category, Item 6, "responds in a timely fashion to the queries" has the highest gap (0.45) compared to other item statements. 
Table 1: Perceived Importance and Actual Practices of Behavioral Performance in Chat Reference Service

\begin{tabular}{|c|c|c|c|c|c|c|}
\hline \multirow{2}{*}{ Rank } & \multirow{2}{*}{ (Item Number) Item Statements } & \multicolumn{2}{|c|}{$\begin{array}{c}\text { *Perceived } \\
\text { Importance (I) }\end{array}$} & \multicolumn{2}{|c|}{$\begin{array}{l}* * \text { Current } \\
\text { Practices (P) }\end{array}$} & \multirow{2}{*}{$\begin{array}{c}\begin{array}{c}\text { Mean } \\
\text { Gap }\end{array} \\
\text { (I-P) }\end{array}$} \\
\hline & & Mean & SD & Mean & SD & \\
\hline \multicolumn{7}{|c|}{ Visibility/ Approachability } \\
\hline 1 & (3) Acknowledges other patrons waiting for service. & 4.41 & 0.746 & 4.13 & 0.691 & 0.28 \\
\hline 2 & (2) Acknowledges patrons by using a friendly greeting to initiate a conversation and willingness to help. & 4.54 & 0.638 & 4.18 & 0.698 & 0.36 \\
\hline 3 & (4) Employs a system of question triage to identify questions and service priorities. & 4.45 & 0.658 & 4.08 & 0.769 & 0.37 \\
\hline 4 & (1) Poised and ready to engage patrons. & 4.41 & 0.673 & 4.03 & 0.755 & 0.38 \\
\hline 5 & (5) Provides prominent, jargon-free pointers to all forms of reference services via the library's web or mobile site. & 4.32 & 0.614 & 3.92 & 0.818 & 0.4 \\
\hline 6 & (6) Responds in a timely fashion to the queries. & 4.42 & 0.655 & 3.97 & 0.821 & 0.45 \\
\hline \multicolumn{7}{|c|}{ Interest } \\
\hline 1 & (1) Focuses complete attention on the patron and his/her information need. & 4.41 & 0.612 & 4.14 & 0.679 & 0.27 \\
\hline 2 & (5) Signals an understanding of the patron's need. & 4.4 & 0.589 & 4.1 & 0.783 & 0.3 \\
\hline 3 & (2) Acknowledges user questions in a timely manner. & 4.41 & 0.653 & 4.08 & 0.717 & 0.33 \\
\hline 4 & (3) Provide assurance that the query is still viable and a response is forthcoming. & 4.42 & 0.655 & 4.01 & 0.764 & 0.41 \\
\hline 5 & (4) Maintains online contact. & 4.31 & 0.744 & 3.87 & 0.812 & 0.44 \\
\hline \multicolumn{7}{|c|}{ Listening/ Inquiring } \\
\hline 1 & (8) Uses closed or clarifying questions to refine the search query. (e.g: “Do you need a book or an article?") & 4.38 & 0.669 & 4.24 & 0.759 & 0.14 \\
\hline 2 & (10) Respects patron privacy; maintain confidentiality after the transaction. & 4.54 & 0.596 & 4.38 & 0.707 & 0.16 \\
\hline 3 & (2) Uses a written language appropriate to the patron and the nature of the transaction. & 4.29 & 0.605 & 4.1 & 0.783 & 0.19 \\
\hline 4 & (3) Allows the patron to fully state his/her information need in his/her own words before responding. & 4.38 & 0.586 & 4.19 & 0.704 & 0.19 \\
\hline 5 & $\begin{array}{l}\text { (9) Maintains objectivity; does not interject value judgments about the subject matter or the nature of the question into the } \\
\text { transaction. }\end{array}$ & 4.35 & 0.699 & 4.15 & 0.774 & 0.2 \\
\hline 6 & (7) Uses open-ended questions to encourage the patron to expand on the request or present additional information. & 4.35 & 0.68 & 4.12 & 0.868 & 0.23 \\
\hline 7 & (4) Identifies the goals or objectives of the patron's research, when appropriate. & 4.4 & 0.631 & 4.13 & 0.762 & 0.27 \\
\hline 8 & (1) Communicates in a receptive, cordial, and supportive manner. & 4.49 & 0.575 & 4.17 & 0.746 & 0.32 \\
\hline
\end{tabular}




\begin{tabular}{|c|c|c|c|c|c|c|}
\hline 9 & (5) Rephrases the question or request and asks for confirmation to ensure accurate understanding. & 4.36 & 0.644 & 4.03 & 0.789 & 0.33 \\
\hline 10 & (6) Seeks to clarify confusing terminology and avoids jargon. & 4.4 & 0.69 & 4.05 & 0.836 & 0.35 \\
\hline \multicolumn{7}{|c|}{ Searching } \\
\hline 1 & (2) Constructs a competent and complete search strategy. & 4.27 & 0.696 & 4.19 & 0.757 & 0.08 \\
\hline 2 & (3) Explains the search strategy to the patron. & 4.4 & 0.651 & 4.29 & 0.775 & 0.11 \\
\hline 3 & (1) Finds out what the patron has already tried, and encourages the patron to contribute his/her ideas. & 4.31 & 0.67 & 4.17 & 0.746 & 0.14 \\
\hline 4 & (6) Attempts to conduct the search within the patron's allotted time frame. & 4.23 & 0.788 & 4.08 & 0.834 & 0.15 \\
\hline 5 & (7) Explains the patron how to use sources when appropriate. & 4.42 & 0.635 & 4.23 & 0.788 & 0.19 \\
\hline 6 & (5) Works with the patron to narrow or broaden the topic when too little or too much information is identified. & 4.35 & 0.699 & 4.15 & 0.823 & 0.2 \\
\hline 7 & (10) Asks the patrons if additional information is needed after results are found. & 4.37 & 0.647 & 4.17 & 0.692 & 0.2 \\
\hline 8 & (4) Works with the patron to evaluate results / revise search terms. & 4.26 & 0.797 & 4.05 & 0.924 & 0.21 \\
\hline 9 & $\begin{array}{l}\text { (9) Recognizes when to refer patrons for more help. This might mean a referral to a subject librarian, specialized library, or } \\
\text { community resource. }\end{array}$ & 4.27 & 0.678 & 4.06 & 0.827 & 0.21 \\
\hline 10 & $\begin{array}{l}\text { (8) Offers pointers, detailed search paths, or names of resources used to find the answer, so that patron can learn to answer } \\
\text { similar questions on his/her own, when appropriate. }\end{array}$ & 4.35 & 0.699 & 4.08 & 0.786 & 0.27 \\
\hline \multicolumn{7}{|c|}{ Follow Up } \\
\hline 1 & (4) Makes the patron aware of other available reference pathways (email, face to face reference). & 4.4 & 0.589 & 4.22 & 0.638 & 0.18 \\
\hline 2 & (3) Consults with other librarians or experts in the field when additional subject expertise is needed. & 4.4 & 0.566 & 4.18 & 0.698 & 0.22 \\
\hline 3 & (2) Encourages the patron to return if he/she has further questions. & 4.35 & 0.699 & 4.1 & 0.766 & 0.25 \\
\hline 4 & (7) Takes care not to end the reference interview prematurely. & 4.42 & 0.655 & 4.15 & 0.774 & 0.27 \\
\hline 5 & (1) Asks the patron if his/her questions have been completely answered. & 4.5 & 0.619 & 4.17 & 0.763 & 0.33 \\
\hline 6 & (6) Refers the patron to other sources or institutions if the query has not been answered to the satisfaction of the patron. & 4.38 & 0.76 & 4.04 & 0.829 & 0.34 \\
\hline 7 & $\begin{array}{l}\text { (5) Makes arrangements with the patron, when appropriate, to set up an individual research appointment to continue } \\
\text { researching the question. }\end{array}$ & 4.29 & 0.723 & 3.9 & 0.877 & 0.39 \\
\hline
\end{tabular}

* 1= Not Important; 2= Slightly Important; 3=Moderately Important; 4= Important; 5= Very Important

**1=Never; 2=Almost Never; 3=Sometimes; 4=Almost Every Time; 5=Every Time 
This indicates that the librarians do not reply to the users immediately, although they rated the behavior as important. Delay to make an initial response and personalize the greetings can affect the service as the Visibility/Approachability has an impact on the reference transaction as a whole and the interview process specifically. It could make the users feel comfortable "in a situation that may be perceived as intimidating, risky, confusing, and overwhelming" (Gottfried and Pennavaria 2017, p. 45). This result seems to be consistent with the previous studies (Walter and Mediavilla 2005; Zhuo et al. 2006) that most of the librarians were able to communicate clearly, but several of them did not greet the users in a friendly manner.

Interest category recorded the second place that having the highest gap (0.350). This gap portrayed that there was lack of practices among the librarians during chat reference sessions. Item 4 "maintains online contact" in this category has the highest gap (0.44) between the perceived importance $(M=4.31)$ and current practices $(M=3.87)$ compared to the other items. This implies that there is a delay in writing or preparing prompts among the librarians in response to the user's query. It may be because librarians are handing multiple tasks such as attending several online users as well as face to face users concurrently. However, this finding seems to be contradicted with two previous studies conducted by Ronan, Reakes and Ochoa (2006) and van Duinkerken, Stephens and MacDonald (2009) who reported that librarians maintained an adequate amount of word contact to keep the user apprised of the search status.

The findings revealed that Follow Up category have the lowest gap (0.283). This indicates that the librarians are aware of the importance of Follow Up and had practiced it to ensure that users are satisfied with the information given.

Listening/Inquiring category revealed the lowest gap (0.238) between the perceived importance $(M=4.394)$ and current practices $(M=4.156)$. This implies that the librarians are aware of the importance of Listening/Inquiring and they have practiced an effective listening and questioning skills for a positive interaction. The finding also showed Item 8 "uses closed or clarifying questions to refine the search query" is the top rated behavior among the 10 items outlined in Listening/Inquiring category with the lowest gap (0.14). It seems that asking a close or straightforward question would result in more successful interaction. This is because the users would provide a specific answer that help the librarian understand better their information needs. This finding is in line with previous study by Ronan, Reakes and Ochoa (2006) who reported 70 percent of the librarians have identified the user's information needs effectively.

Searching category shows matching behavior in term of the perceived importance $(M=4.323)$ and its actual practices $(M=4.141)$ among the librarians as recorded by the lowest gap (0.182). This indicates that librarians evaluate searching as an important element in chat reference service. The librarians appear to follow the guidelines in order to provide accurate and relevant information to users' query. However, this result contradicts past study by van Duinkerken, Stephens and MacDonald (2009) who reported a poor performance in compliance to RUSA recommended searching behaviors among the librarians possibly due to the time constraints users faced as they were in hurry to get the information.

\section{DISCUSSIONS}

The findings highlighted that the perceived importance of behavioural performance in the interaction during the chat reference service as outlined in RUSA behavioral guidelines was 
rated higher than the current practices by the librarians. This shows that the librarians were aware of the importance of RUSA behavioral guidelines, however they did not fully comply with these recommendations as shown in the lack of practices among them. In addition, the results also showed mixed compliance to the guidelines as presented through the difference in the gap analysis between perceived importance and current practices for every behavior item statement.

There are several factors that could contribute to the non-compliance with the guidelines. For example, the nature of the question asked by users only required a simple and quick responses where the questions ranged from ready reference (simple factual information) to library information inquiries (library policies, procedures, services). Thus, it does not require to conduct an in depth interview during the chat reference service.

Another factor may be due to the time constraint for both librarians and users. Librarians who are attending to more than one user at the same time may not be able to respond in a timely manner and unable to provide effective online reference interview. Similarly, the users might be in a hurry to get the information required and do not have time for a long explanation on how to search. Apart from that, the lack of training received by the librarians should be considered as a factor since effective provision of reference service requires skills, knowledge, and competencies as outlined in the RUSA behavioral guidelines.

The study demonstrated that librarians generally performed well in Searching category, but they lack skills in Visibility/Approachability category that indicates them as less pleasant. Based on the finding, librarians tend to focus on constructing a competent and complete search strategy in order to avoid wrong search results as well as multiple searches that would lengthen the time of the chat session. Therefore, a proper and effective searching behavior during chat reference transaction is important to find information needed by the users.

In general, the finding reported that the academic librarians in Malaysia are at par with a standard guideline in delivering chat reference services. They followed the guidelines as stated in RUSA while handling chat reference services. The finding showed that there was relatively no mean difference in the Visiblity/Approachability, Interest, Listening/Inquiring, Searching and Follow-Up between perceived importance and actual practices among librarians in Malaysia. The librarians provide chat reference services based on what they perceived important according to RUSA as a standard guideline. This is evident as the analysis of librarians' perceived importance and current practice were generally aligned.

However, improvement is needed in the area of friendliness and interest. The finding shows there is a need for the librarians to comply with the Visibility/Approachability and Interest for effective information assistance especially to respond in a timely manner and maintain online contact. This is because, most users will expect to have their inquiries responded in a reasonable time frame when getting online reference help. Users can be impatient and may not wait for assistance if they are kept waiting without being acknowledged the search status.

\section{CONCLUSION}

This study assess librarians' perceived importance and actual practices of behavioral performance during chat reference interaction in accordance to RUSA Guidelines for Behavioral Performance. The finding is useful for librarians to provide effective chat reference transaction that adhere to RUSA guidelines for virtual reference services. Unveiling gaps 
between librarians' perceived importance and actual practices is beneficial to identify areas that need improvement. The finding could also provides an empirical benchmark for evaluating chat reference services.

This study however is limited by self-reported survey from academic library setting. Therefore generalization of the finding should be treated with caution. It is recommended that librarians' perceived importance of the chat reference should not be used as the basis for understanding their actual practices of the service. Further study could explore in depth the reasons behind mixed compliance to RUSA guidelines that may perhaps provide more understanding on why librarians do not adhere to the guidelines and what factors leads to librarian action or inaction of the recommended behavior.

\section{ACKNOWLEDGEMENT}

This research received no specific grant from any funding agency in the public, commercial, or not-for profit sectors.

\section{REFERENCES}

Al-Momani, M. M. 2016. Gap Analysis between Perceptions and Expectations of MedicalSurgical Patients in a Public Hospital in Saudi Arabia. Medical Principles and Practice, Vol. 25, no. 1:79-84. Available at: https://doi.org/10.1159/000441000.

Akeriwa, M., Penzhorn, C. and Holmner, M. 2015. Using Mobile Technologies for Social Media Based Library Services at the University of Development Studies Library, Ghana. Information Development, Vol. 31, no. 3: 284-293. Available at: https://doi.org/10.1177/0266666913515898.

Armann-Keown, A., Cooke, C. A. and Matheson, G. 2015. Digging deeper into virtual reference transcripts. Cooke Reference Services Review, Vol. 43, no. 4: 656-672. Available at: https://doi.org/10.1108/RSR-04-2015-0024.

Arnold, J. and Kaske, N. 2005. Evaluating the quality of a chat service. Portal: Libraries \& the Academy, Vol. 5, no. 2: 177-193.

Arvin, S. D. and Kaiser, A. 2012. Case study of synchronous virtual reference in an academic library. Internet Reference Services Quarterly, Vol. 17, no. 2: 83-93.

Arya, H. and Mishra, J. 2011. Oh!Web 2.0, virtual reference service 2.0, tools \& techniques (I): A basic approach. Journal of Library \& Information Services in Distance Learning, Vol. 5, no. 4: 149-171.

Beaton, B. 2012. New technologies for virtual reference: A look at skype and Twitter. Available at: https://www.lib.umich.edu/files/departments/SkypeTwitter\%20112912.pdf.

Brown, S. 2010. Likert scale examples for surveys. Available at: http://www.extension.iastate.edu/ag/staff/info/likertscaleexamples.pdf.

Brown, S. W. and Swartz, T. A. 1989. A Gap Analysis of Professional Service Quality. Journal of Marketing, Vol. 53, no. 2:92-98. Available at: https://doi.org/10.2307/1251416.

Chowdhury, G. and Margariti, S. 2004. Digital reference services: a snapshot of the current practices in Scottish libraries. Library Review, Vol. 53, no. 1:50-60. Available at https://doi.org/10.1108/00242530410514793.

Chu, S. K.-W. and Du, H. S. 2012. Social networking tools for academic libraries. London: SAGE Publications. Journal of Librarianship and Information Science, Vol. 45, no. 1:64-75. Available at: https://doi.org/10.1177/0961000611434361. 
Desai, C. M. and Graves, S. J. 2008. Cyberspace or face-to-face: the teachable moment and changing reference mediums. Reference \& User Services Quarterly, Vol. 47, no. 3: 242254.

Devlin F., Currie, L. and Stratton J. 2008. Successful approaches to teaching through chat. New Library World, Vol. 109, no. 5/6: 223-234. Available at: https://doi.org/10.1108/03074800810873579.

Fernandez, J. (2004). Facing live reference. Online, Vol. 28, no. 3: 37-40.

Fuller, K. and Dryden N. H. 2015. Chat reference analysis to determine accuracy and staffing needs at One Academic Library. Internet Reference Services Quarterly, Vol. 20, no. 34:163-181. Available at: https://doi.org/10.1080/10875301.2015.1106999.

Fullerton, V. 2002. IFLA digital reference standards project. Available at: http://www.ifla.org/node/1776.

Gatten, J. N. and Radcliff, C. J. 2001. Assessing reference behaviors with unobtrusive testing. In D. P.Wallace \& C. Van Fleet (Eds.), Library evaluation: A casebook and can-do guide (pp. 105-115). Englewood, CO: Libraries Unlimited.

Gottfried, J. and Pennavaria, K. 2017. Providing reference services: A practical guide for librarians (Practical Guides for Librarians), Maryland: Rowman \& Littlefield Publishers.

Hill, J. B., Madarash-Hill, C. and Allred, A. 2007. Outsourcing digital reference: The user perspective. Reference Librarian, Vol. 47, no. 2:57-74.

Jaarsma, T., Strömberg, A., Fridlund, B., De Geest, S., Mårtensson, J., Moons, P., Norekval, T. M., Smith, K., Steinke, E. and Thompson, D. R. 2010. Sexual counselling of cardiac patients: Nurses' perception of practice, responsibility and confidence. European Journal of Cardiovascular Nursing, Vol. 9, no. 1: 24-29. Available at: https://doi.org/10.1016/j.ejcnurse.2009.11.003.

Jia, L. 2007. The evaluation of worldwide digital reference services in libraries. Oxford: Chandos.

Krejcie, R. V. and Morgan, D. W. 1970. Determining sample size for research activities. Educational and Psychological Measurement, Vol. 30: 607-610.

Kwon, N. and Gregory, V.L. 2007. The effects of librarians' behavioral performance on user satisfaction in chat reference services. Reference \& User Services Quarterly, Vol. 47, no. 2: 137-148.

Kwon, N. 2006. User Satisfaction with referrals at a collaborative virtual reference service. Information Research, Vol. 11, no. 2. Available at: http://www.informationr.net/ir/112/paper246.html.

Lagzian, F., Abrizah, A. and Wee, M. C. 2015. Measuring the gap between perceived importance and actual performance of institutional repositories. Library and Information Science Research, Vol. 37, no. 2: 147-155. Available at: https://doi.org/10.1016/j.lisr.2014.06.007.

Maness, J. M., Naper, S. and Chaudhuri, J. 2009. The good, the bad, but mostly the ugly: adherence to RUSA guidelines during encounters with inappropriate behavior online. Reference \& User Services Quarterly, Vol. 49, no. 2: 151-162.

Matteson, M. L., Salamon, J. and Brewster, L. 2011. A systematic review of research on live chat service. Reference \& User Services Quarterly. Vol. 51, no. 2: 172-189.

Maximiek, S., Rushton, E. and Brown, E. 2010. Coding into the great unknown : analyzing instant messaging session transcripts to identify user behaviors and measure quality of service. College \& Research Libraries, Vol. 71, no. 4: 361-373. Available at: https://doi.org/10.5860/crl-48r1.

Morin, A. C. 2004. Chapter 9: Approaching best practices and guidelines for digital reference. In The Virtual Reference Experience: Integrating Theory into Practice. London: NealSchuman Publishers Inc. 
Moyo, L. 2006. Virtual reference services and instruction: an assessment. The Reference Librarian, Vol. 46, no. 95/96: 213-30.

Nilsen, K. and Ross, C. S. 2006. Evaluating virtual reference from users' perspective. In Assessing reference and user services in a digital age (pp.53-79). NY: The Haworth Press.

O'Dell, S. 2010. Opportunities and obligations for libraries in a social networking age: a survey of web 2.0 and networking sites. Journal of Library Administration, Vol. 50, no. 3: 237251.

Philips, S. and Borg, S. 2009. Exploring tensions between teachers' grammar teaching beliefs and practices. System, Vol. 37, no. 3: 380-390. Available at: https://doi.org/10.1016/j.system.2009.03.002.

Platt, J. and Benson, P. 2010. Improving the virtual reference experience: How closely do academic libraries adhere to RUSA guidelines? Journal of Library and Information Services in Distance Learning, Vol. 4, no. 1-2: 30-42.

Pomerantz, J. and Luo, L. 2006. Motivations and uses: evaluating virtual reference service from the users' perspective. Library \& Information Science Research, Vol. 28, no. 3: 350-73.

Pun, R. 2015. WeChat in the library: promoting a new virtual reference service using a mobile app. Library Hi Tech News, Vol. 32, no. 6: 9-11. Available at: https://doi.org/10.1108/LHTN-03-2015-0017.

Radford, M. L. and Connaway, L. S. (2012). Not dead yet! A longitudinal study of query type and ready reference accuracy in live chat and IM reference. Library \& Information Science Research, Vol. 35, no. 1: 2-13. Available at: https://doi.org/10.1016/j.lisr.2012.08.001.

Ronan, J., Reakes, P. and Ochoa, M. 2006. Application of reference guidelines in chat reference interactions: a study of online reference skills. College \& Undergraduate Libraries, Vol. 13, no. 4: 3-30.

RUSA. 2004. Guidelines for the behavioral performance of reference and information service providers. Available at: http://www.ala.org/Template.cfm?Section=Home\&template= /ContentManagement/ContentDisplay.cfm\&ContentID=26937.

RUSA. 2008. Definitions of reference. Available at: http://www.ala.org/ rusa/guidelines/definitionsreference.

RUSA. 2010. Guidelines for implementing and maintaining virtual reference services, Available at:http://www.ala.org/rusa/sites/ala.org.rusa/files/content/resources/guidelines/virtu al-reference-se.pdf.

RUSA. 2013. Guidelines for the behavioral performance of reference and information service providers. Available at: http://www.ala.org/rusa/resources/guidelines/ guidelinesbehavioral.

Saxton, M. L. and Richardson, J. V. 2002. Understanding reference transactions: transforming an art into a science. New York: Academic Press.

Shachaf, P. and Horowitz, S. 2006. Are virtual reference services color blind? Library \& Information Science Research, Vol. 28, no. 4: 501-520.

Schwartz, H. R. 2014. The application of RUSA standards to the virtual reference interview. Reference \& User service quarterly, Vol. 54, No. 1: 8-11.

Vagias, W. M. 2006. Likert-type scale response anchors. Available at: http://www.clemson.edu/centers-institutes/tourism/documents/sample-scales.pd.

Valentine, G. and Moss, B. D. 2017. Assessing reference service quality: a chat transcript analysis. Paper presented at Association of College and Research Libraries Conference, 28 March 2017 at Baltimore, Maryland. Available at: https://kuscholarworks.ku.edu/handle/1808/25179.

van Duinkerken, W., Stephens, J. and MacDonald, K. I. 2009. The chat reference interview: seeking evidence based on RUSA's guidelines: a case study at Texas A\&M University Libraries. New Library World, Vol. 110, no. 3/4 107-121. Available at http://www.emeraldinsight.com/10.1108/03074800910941310. 
Walter, V. A. and Mediavilla, C. 2005. Teens are from Neptune, librarians are from Pluto: an analysis of online reference transactions. Library Trends, Vol. 54, no. 2: 209-227.

Whitlatch, J. B. 2001. Evaluating reference services in the electronic age. Library Trends, Vol. 50, no. 2: 207-217.

Yang, S. Q. and Dalal, H. A. 2014. Delivering virtual reference services on the web: an investigation into the current practice by academic libraries. The Journal of Academic Librarianship, Vol. 41, no. 1: 68-86. Available at: https://doi.org/10.1016/j.acalib.2014.10.003.

Zhuo, F., Love, M., Norwood, S. and Massia, K. 2006. Applying RUSA Guidelines and the analysis of chat reference transcripts. College and Undergraduate Libraries, Vol. 13, no. 1: $75-88$. 